\title{
Sanitary practices and occurrence of zoonotic conditions in cattle at slaughter in Morogoro Municipality, Tanzania: implications for public health
}

\author{
ERICK V.G. KOMBA ${ }^{1 *}$, EWALDO V. KOMBA², ERNATUS M. MKUPASI ${ }^{1}$, ALBANO O. MBYUZI ${ }^{3}$, \\ SHAABANI MSHAMU ${ }^{4}$, DENICE LUWUMBA ${ }^{3}$, ZABLON BUSAGWE ${ }^{1}$ and ALEXANDA MZULA ${ }^{5}$ \\ ${ }_{1}^{1}$ Department of Veterinary Medicine and Public Health, Sokoine University of Agriculture, P. O. Box 3021, \\ Morogoro, Tanzania \\ ${ }^{2}$ Department of Internal Medicine, Muhimbili University of Health and Allied Sciences, P. O. Box 65001, Dar \\ es Salaam, Tanzania \\ ${ }^{3}$ Veterinary Investigation Centre, Southern Zone, P.O. Box 186, Mtwara, Tanzania \\ ${ }^{4}$ Department of Veterinary Physiology, Biochemistry, Pharmacology \& Toxicology, Sokoine University of \\ Agriculture, P. O. Box 3017, Morogoro, Tanzania \\ ${ }^{5}$ Department of Veterinary Microbiology and Parasitology, Sokoine University \\ of Agriculture, P. O. Box 3019, Morogoro, Tanzania
}

\begin{abstract}
As meat consumption is increasing worldwide to cover for protein demands, also raise concerns and challenges regarding meat hygiene and safety. The current one year follow up study aimed at investigating on sanitary practices and occurrence of zoonotic conditions, during postmortem examination, in cattle at slaughter in Morogoro Municipality abattoir. Sanitary practices were assessed through direct observation where as routine post-mortem inspection procedures were employed to detect zoonotic conditions in cattle at slaughter. During the study period a total of 30,713 cattle were slaughtered and inspected at the abattoir. Results revealed poor hygienic practices at the level of abattoir surrounding, the slaughter operation area, personnel as well as meat vans. Whole carcasses, lungs, livers, hearts and heads were condemned due to zoonotic conditions at rates of $0.026 \%, 1.96 \%, 1.61 \%, 0.02 \%$ and $0.21 \%$ respectively. Bovine tuberculosis, Cysticercus bovis cysts, fasciolosis and hydatidosis were the responsible zoonotic conditions for the condemnations. Bovine tuberculosis was a leading zoonotic cause of condemnations accounting for $95.7 \%$ of lungs and $100 \%$ of all head and carcass condemnations. Cysticercus bovis cysts were ranking the second in serving as causes of condemnations closely followed by fasciolosis and lastly hydatidosis. Occurrence of disease conditions with zoonotic implication in cattle at slaughter, meant for human consumption, may pose significant economic and public health risks to especially disaster-prone marginalized communities. Thus, there is a need to introduce appropriate control measures of livestock diseases to minimize the rate of infection; and eventually reduce economic losses and safeguard public health.
\end{abstract}

Key words: sanitary practices, zoonoses, abattoir, cattle, public health, Tanzania

\section{Introduction}

Most of the slaughter-facilities in Tanzania receive slaughter stocks from the traditional livestock sector which constitutes more than $98 \%$ of the total livestock population in the country (MAFS, 2002). The traditional livestock sector is characterized by poor animal genetic make-up, poor management and disease burden. Animal diseases seriously affect the productivity of livestock population in the sector. Control of livestock diseases in

\footnotetext{
* Correspondence: Dr. Erick V.G. Komba; E-mail: ekomba@suanet.ac.t.z/ babagrid@yahoo.com
} 
Tanzania is poorly achieved because of inadequate veterinary services especially in rural areas (Kambarage et al., 1995; Nonga et al., 2009; Mellau et al., 2010, 2011). The inadequate veterinary services in rural areas are mainly due to shortage of veterinary staff, poor infrastructure, and inadequate diagnostic facilities, drugs and biologicals. As a result animals brought for slaughter into urban areas from the rural traditional sector are rarely detected during ante-mortem examination and hence the animals proceed into slaughter.

Diseases and infections that are naturally transmitted between vertebrate animals and humans (zoonoses) account for $60 \%$ of all infectious disease pathogens and $75 \%$ of all emerging pathogens (WHO, 2010; Woolhouse \& Gaunt, 2007). Humans can acquire these infections directly from contact with sick or carrier animals, or through the ingestion of contaminated foodstuffs or from other environmental sources (Lahuerta et al., 2011). It has been suggested that human population density, human population growth, wildlife host species richness and low latitude are predictors for the emergence of zoonotic diseases (Jones et al., 2008). The severity of these diseases in humans can vary from mild symptoms to chronic sequelae or life-threatening conditions (Lahuerta et al., 2011). The effects of zoonoses are accentuated among marginalized groups as the poor tend to have closer interactions with animals and are further isolated from accessible health services. Many endemic zoonoses have been documented in developing countries and elsewhere, most of which disproportionately affect poor and marginal communities. These include diseases like cysticercosis, trichinellosis, toxoplasmosis, hydatidosis, campylobacteriosis, Rift Valley fever and tuberculosis (Gracey et al., 1999).

The monitoring and surveillance of emerging infectious and zoonotic diseases in food animals are important components of food safety systems. The emergence of H5N1 influenza and bovine spongiform encephalopathy (BSE) has increased the concern of emerging zoonotic diseases to both public and animal health (Brown, 2004). Consequently, researchers attention dwells on novel approaches, such as syndromic surveillance, for detecting emerging diseases in food animals at various points along the farm-to-fork continuum (Vourc'h et al., 2006; Van Metre et al., 2009).

Abattoirs have played an important role in the surveillance of various diseases of human and animal health importance (Vilas et al., 2008; Hadorn et al., 2008; Karama et al., 2008). Surveillance at the abattoir allows for all animals passing into the human food chain to be examined for unusual signs, lesions or specific diseases. A study evaluating surveillance systems for bovine tuberculosis in Switzerland found that surveillance during meat inspection at the slaughterhouse had the highest sensitivity for identifying the disease compared to passive clinical surveillance of humans or cattle on farms (Hadorn et al., 2008). Changes in the incidence of lesions at slaughter may provide important information for syndromic surveillance of diseases of animal, public health, and food safety significance. Consequently, the objective of the present study was to assess sanitary practices and identify zoonotic conditions of cattle detected at abattoir during post-mortem meat inspection in Morogoro Municipality in Tanzania.

\section{Materials and methods}

\section{Study design and study animals}

This study was conducted at Morogoro Municipality abattoir in Tanzania. Morogoro abattoir is government owned and managed by the Morogoro Municipal Council. Morogoro 
Municipality $\left(6^{0} 49^{\prime} S-37^{\circ} 40 \mathrm{E}\right)$ is located at about $200 \mathrm{~km}$ west of Dar es Salaam. The Municipality has a total population of about 228,863 (113,639 males and 115,224 females) (URT 2002).

This was a prospective abattoir survey, undertaken for a period of 1 year from February 2010 to January 2011. In Tanzania, the livestock setup is such that only adult animals are presented for slaughter. All the animals presented for slaughter at the abattoir and subjected to post-mortem inspection during the study period were included in this study.

\section{Data collection}

In the present study, assessment of sanitary practices of the abattoir involved the following parameters; location, presence of a fence, source and availability of potable water, slaughter place layout and availability of basic facilities, waste disposal, presence of toilets and bathrooms, protective gears for the personnel, hygiene of workers and the surroundings, hides handling and meat vans hygiene.

Inspection of the slaughtered animals was carried by both the resident meat inspectors involved in routine meat inspection at the abattoir and the researchers. Involvement of the researchers, which was three times every week, was seeking to assess the sanitary practices and also attaining quality control of the post-mortem inspection data. Usually, the meat inspectors carry out this work without daily supervision by qualified veterinarians, who visit the premises only when there are problems.

The procedures adopted for inspection of slaughter cattle employ meat inspection protocols issued by Tanzania Meat Inspection Act of 1993. The procedures involve visual examination, palpation and incision of muscles and intact organs such as the lungs, liver, spleen, heart, kidneys, tongue and various regional lymphnodes. For some diseases like bovine tuberculosis and cysticercosis further thorough examinations of other parts, or body systems are considered whenever lesions are detected in one of examined organs. Findings from meat inspection were recorded on meat inspection disease analysis report format.

\section{Data analysis}

Data were analysed using Statistical Package for Social Sciences version 11.5. Descriptive statistics were computed to determine the prevalence of zoonotic infections in examined slaughter cattle. Graphics were produced in Microsoft Excel.

\section{Ethical consideration}

The Institutional Review Board of the Sokoine University of Agriculture approved this study. The permission to carry out the study at the abattoir was sought from the Morogoro Municipal Veterinary Officer. Meat inspection was effected by qualified, registered government employed inspectors using standard procedures.

\section{Results}

\section{Descriptive}

During this period (February 2010-January 2011), a total of 30,713 cattle were slaughtered and inspected. The average number of animals slaughtered per day was $86 \pm 14$.4. More than 95\% of the animals slaughtered were of indigenous type belonging to Tanzanian Short-horn Zebu (TSZ) and Boran breeds. A few slaughter cattle were of exotic breeds most of them 
disposed as culls. The average carcass weight was $97.5 \pm 25.4 \mathrm{~kg}$ for indigenous breeds and $158.25 \pm 82.85 \mathrm{~kg}$ for exotic cattle. Indigenous cattle were purchased from cattle auctions around Morogoro Municipality; namely Dumila, Mkata, Melela, Misongeni, Nanenane and Dakawa. Apart from the auction level, it was difficult to precisely trace back the geographical origins of all the animals slaughtered due to lack of reliable animal identification methods. Most of the slaughter animals were sent to the abattoir by trekking means.

\section{Sanitary practices}

Morogoro abattoir is located within an area close to a busy road and surrounded with residential houses with no room for expansion. It is not fenced and hence provides room for being accessed by vermin. The abattoir, receiving water from the community supply, suffers scarce availability of potable water during dry seasons. According to the abattoir staff water may flow two or three days a week during this season. Drainage infrastructures at the abattoir were available but open and allow standing of liquid wastes including blood, floor washings and other materials to be conveyed to pits. Washing of animal products involved only the intestines. Similarly, the floor on which all the slaughter operations are carried on was not regularly cleaned with water (every second day) because of water shortage. During the water shortage periods washing of these items were done using water fetched from other sources away from the abattoir.

The abattoir building had crevices on the walls and the floor such that proper cleaning was compromised. It was provided with well-distributed artificial light but of inadequate intensity. There was suitable and sufficient means of ventilation to the external air which was however interfered by animal and human overcrowding. All the processes of carcass dressing i.e. bleeding, skinning, evisceration and portioning were done manually on the floor. The abattoir layout considered both clean and unclean operations as recommended but these were not efficiently separated as they were demarcated by an imaginary line thereby allowing occasional overlaps. Basic sanitary amenities such as detergents, disinfectants and clothes for hand drying were made available but at irregular and/or deficient supplies. Occasional hand washing followed by drying on own worn clothes was observed among some workers. Sterilizing agents such as boiling water or live steam were always lacking during slaughter operations.

The two abattoir toilets though were thorough cleaned weekly, were always in unhygienic manner which further compromised good hygienic practices of a food industry. Slaughter process and eventually meat inspection was always closely witnessed by animal owners whose health status was unknown. The abattoir lacked cold room storage and the meat was distributed to the market on the day of slaughter. The facility was provided with a place for drying hides situated close to slaughter operations area attracting flies due to emission of bad smell as a result of decomposition. The abattoir had a waste disposal facility situated close to slaughter operations area, the situation which attracted cats, flies, craws and stray dogs. The facility was provided with an incinerator which was not operating during the study period. Most meat vans were pickup vehicles each with an open body. They were of poor hygiene and during meat transportation butchers would also get in and sometimes stepped on meat. 
During the 12 month period of the study cattle whole carcasses, lungs, livers, heads and hearts were condemned due to detection of zoonotic conditions during post-mortem examination. The condemnations of the organs/parts were associated with detection of bovine tuberculosis, Cysticercus bovis cysts, liver flukes and hydatid cysts. The frequencies of condemnation of each part/organ are shown in Figure 1. Figure 2 summarises the proportion contribution of each detected zoonotic condition to the total condemnations. Whole carcass and head condemnations were solely due to detections of bovine tuberculosis. Condition specific condemnations of lungs, livers and hearts are shown in Table 1.

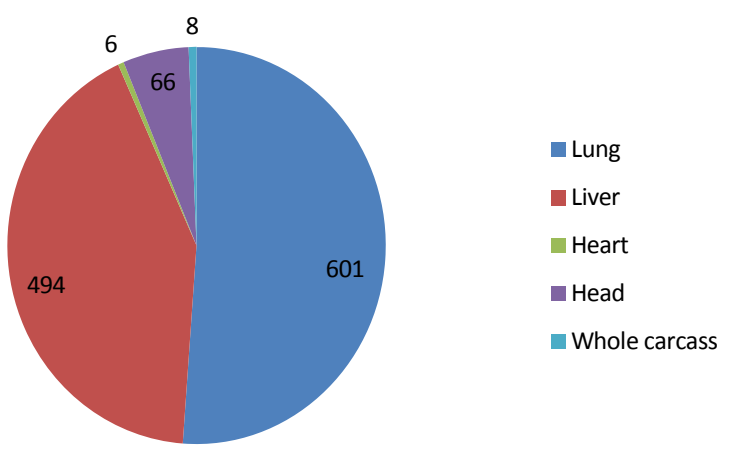

Figure 1: Frequency of abattoir condemnation due to detection of zoonotic conditions at postmortem examination

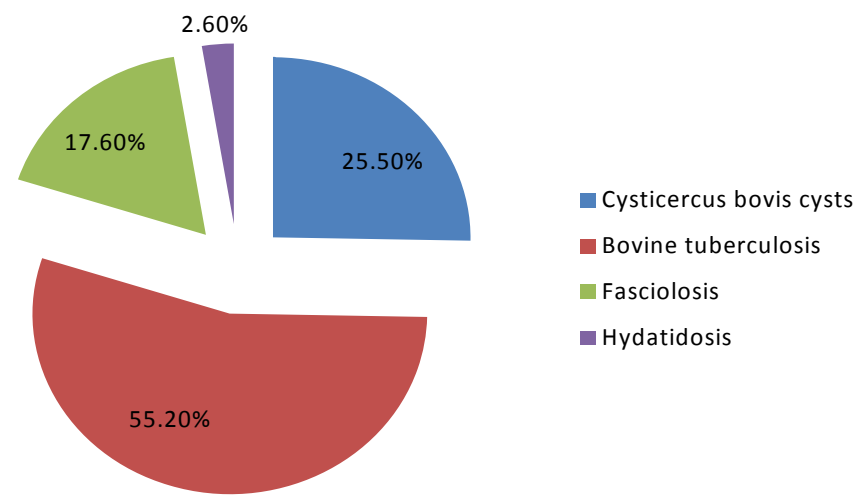

Figure 2: Proportion contributions of different zoonotic conditions to total condemnation of slaughter cattle organs/parts

Table 1: Zoonotic conditions associated with condemnations of cattle organs during post-mortem inspection at Morogoro Municipal abattoir

\begin{tabular}{lll} 
Organ & Condition & Condemnatio \\
\hline Lung & Bovine tuberculosis & $575(1.87 \%)$ \\
& Hydatidosis & $14(0.046 \%)$ \\
& Calcified cysts & $12(0.04 \%)$ \\
Liver & Fasciolosis & $207(0.67 \%)$ \\
& Hydatidosis & $17(0.055 \%)$
\end{tabular}




\section{Discussion}

Being a key element in the production and distribution chain for meat it is essential that a slaughterhouse be as hygienic as possible in order to prevent the spread of both human and animal diseases as well as to reduce economic losses due to premature spoilage of meat caused by contamination. According to Biu et al. (2006) many abattoirs and slaughter slabs in developing countries are poorly constructed, have poor slaughter and meat inspection facilities and qualified meat inspectors are always inadequate. The obvious hygiene problem and inadequate meat inspection always causes illness and disease (Hedberg et al., 1992; Joshi et al., 2003). In the present study it was witnessed that the abattoir, surroundings, personnel and also meat vans were in poor hygienic conditions. This has a huge public health implication as it highlights on potential for possibilities of transmitting animal, human and environmental derived pathogens to consumers. More than 100,000 people are affected annually by food borne infections which in some cases are caused by bad food hygiene in slaughter houses or in households ((Tassew et al., 2010).

The present study observed bovine tuberculosis (BTB) occurring at higher levels than any other zoonotic condition during the study period. It is a chronic infectious disease that affects a wide range of mammals, including domestic cattle and humans (Morris et al., 1994). The disease remains an important public health concern worldwide as a result of deficiencies in preventing and/or controlling measures targeting the spread of its causative agent Mycobacterium bovis (Etter et al., 2006; Thoen et al., 2006a). Although human TB is mainly caused by $M$. tuberculosis, in regions where bovine TB is prevalent in animals, human TB cases due to M. bovis may also occur (O'Reilly \& Daborn 1995; Thoen et al., 2009) resulting from ingesting contaminated un-pasteurized milk and raw meat and also by inhaling cough spray from infected livestock (O'Reilly \& Daborn 1995; Cosivi et al., 1998; Ayele et al., 2004). The observed correlation between the prevalence of M. bovis infection in humans and that of local cattle populations highlights the potential threat of this disease for humans. The threat may be immense in rural communities where people have a very close relationship with the animals and milk pasturalization rarely practiced.

The global prevalence of human tuberculosis due to $M$. bovis has been estimated at $3.1 \%$ of all human tuberculosis cases, accounting for $2.1 \%$ and $9.4 \%$ of pulmonary and extra pulmonary TB cases respectively (Cosivi et al., 1998). Population growth, co infection of TB with HIV/AIDS, and widespread development of drug-resistant strains have complicated the morbidity and mortality of TB cases in humans and significantly increased the cost associated with the use of multiple drug therapy (Daborn and Grange, 1993; O'Reilly \& Daborn 1995; Corbett et al., 2003, 2006; WHO, 2009; Thoen et al., 2006b; 2009).

The public health and economic consequences of infection of cattle with metacestodes of the worldwide occurring human tapeworm, Taenia saginata, are considerable (Pawlowski \& Murrell, 2001). In the present study the metacestodes (cysts) featured as the second common cause of organ condemnations. As previously noted (Geerts et al., 1980; McLauchlan, 1981), compared with viable cysts, degenerating parasites were more commonly found at post-mortem. These are less easily recognizable because of the loss of familiar gross and microscopic architecture (Silverman \& Hulland, 1961). The adult stage of Taenia saginata is one of the most common pathogenic cestode in humans (Bordon, 1992). Humans are at a risk of infection when raw or undercooked beef harbouring a viable cyst is consumed (Bordon, 1992; Ogunremi et al., 2004). Infected individuals may remain 
asymptomatic for years, and the only symptom may be the spontaneous passage of proglottids. However, nonspecific symptoms, such as vague abdominal pain, nausea, vomiting, diarrhoea and weight loss can be present (Karanikas et al., 2007). Although the tapeworm seems to be a benign parasitic disease, it can lead to serious surgical gastrointestinal system complications that are seldom reported in the medical literature (Chirdan et al., 2001; Jongwutiwes et al., 2004; Karanikas et al., 2007).

Fasciolosis was among the zoonotic causes associated with organ condemnations in the present study. The disease was a leading cause of liver condemnations in slaughter cattle. Other studies in the country (Hyera, 1984; Kambarage et al., 1995; Mwabonimana et al., 2009; Nonga et al., 2009; Mellau et al., 2010, 2011) also found the disease to be the commonest cause of cattle liver condemnations. Studies involving live animals have also been conducted in country (Keyyu et al., 2005, 2006; Swai et al., 2006), reporting prevalence as high as $94 \%$ in traditional cattle stocks. According to Mas-Coma et al. (2005) the disease is an emerging/re-emerging zoonosis in many countries as a consequence of many phenomena related to environmental changes and man made modifications. Together with other trematodiases the disease is included in a list of important helminthiases with a great impact on human development. The proportion contributions of fasciolosis to total organ condemnations in the present and other studies does not necessarily reflect the magnitude of the infection in slaughter stock. This is because there are many light infections in which affected parts are trimmed and the remaining portion passed for human consumption; and these are not recorded. Liver fluke infestation rarely causes mortalities in cattle, and much of the economic importance of the disease is due to its effect on production and the losses owing to condemnations of the livers (Kambarage et al., 1995).

Echinococcosis or hydatid disease assumes a cosmopolitan distribution but the disease is endemic in the Mediterranean, Africa, Middle East, South America, Australia, Russia, and China where livestock, mainly sheep and cattle, are raised with dogs who act as the definitive hosts for the adult phase of the echinococcal tapeworm (Eckert \& Deplazes 2004; Foster \& Hertz, 2010; Dakkak, 2010; Sotiraki \& Chaligiannis, 2010). Factors contributing to the increase of prevalence and to the spreading of the disease in endemic areas include the diversity of livestock production systems (predominantly extensive, traditional animal husbandry), small, ill-equipped and unsupervised slaughter-houses, illegal and family slaughtering, low public awareness of hydatid disease, and the high population of stray dogs (Dakkak, 2010). The disease contributed $2.6 \%$ of the total condemnations in the present study highlighting its presence in traditional cattle herds. Human infections have been reported in pastoral communities in the country (Ernest et al., 2009). Apart from exerting health effect to both humans and animals, hydatid cysts have important economic consequences (Torgerson, 2003). Human-associated economic losses arise through diagnostic cost, surgical or chemotherapeutic treatment, hospitalization, convalescence, life impairment and fatalities (Torgerson, 2003). In animals economic losses are associated with decreases in carcass weight, milk production and fertility rates, and from increased condemnation of viscera. Previous studies in the country and elsewhere in Africa (Macpherson et al., 2004; Kebede et al., 2008; Nonga \& Karimuribo, 2009) also showed evidence of existence of the disease in domestic animals. Poor sanitation and hygiene, and unrestricted disposal of animal viscera post-slaughter may be responsible for the high prevalence of echinococcosis. 
In conclusion, zoonoses are prevalent in cattle destined for human consumption in Morogoro Municipality suggesting serious public health implications. Since zoonoses are a result of complex interplay of factors that typically impact poor populations, they are a significant barrier to achieving the Millennium Development Goals in low and middle income countries. We therefore advocate inter-sectoral collaborations and pooling of resources in research, policy and program implementation, as promoted by the "one health" approach to allow financially efficient and more innovative strategies for zoonoses prevention and control both in human and animal populations. Effective control strategies require controlling infections in animal populations, liaising veterinary and medical efforts, active involvement of the populations at risk, and good health systems.

\section{Acknowledgements}

This study received a financial support from the Tanzania Higher Education Student Loans Board, their support is highly appreciated. The authors are very grateful for the kind cooperation of staff in the Municipal Livestock Office, Morogoro.

\section{References}

Ayele, W.Y., Neill, S.D., Zinsstag, J., Weiss, M.G. \& Pavlik, I. (2004) Bovine tuberculosis: an old disease but a new threat to Africa. International Journal of Tuberculosis and Lung Disease 8, 924-937.

Biu, A.A., Ahmed, M.I. \& Mshelia, S.S. (2006) Economic assessment of losses due to parasitic diseases common the Maiduguri abattoir, Nigeria. African Scientist 7, 143-145.

Bordon, L.M. (1992) Intestinal obstruction due to Taenia saginata infection: A case report. Journal of Tropical Medicine and Hygiene 95, 352-353.

Brown, C. (2004) Emerging zoonoses and pathogens of public health significance - an overview. Revue Scientifique et Technique 23, 435-442.

Chirdan, L.B., Yusufu, L.M., Ameh, E.A. \& Shehu, S.M. (2001) Meckel's diverticulitis due to Taenia saginata: case report. East African Medical Journal 78, 107-108.

Corbett, E.L., Marston, B., Churchyard, G.J. \& De Cock, K.M. (2006) Tuberculosis in subSaharan Africa: opportunities, challenges, and change in the era of antiretroviral treatment. Lancet 367, 926-937

Corbett, E.L., Watt, C.J., Walker, N., Maher, D., Williams, B.G., Raviglione, M.C. \& Dye, C. (2003) The growing burden of tuberculosis: global trends and interactions with the HIV epidemic. Archives of Internal Medicine 163, 1009-1021.

Cosivi, O., Grange, J.M., Daborn, C.J., Raviglione, M.C., Fujikura, T., Cousins, D., Robinson, R.A., Huchzermeyer, H.F., de Kantor, I., Meslin, F.X. (1998) Zoonotic tuberculosis due to Mycobacterium bovis in developing countries. Emerging Infectious Diseases 4, 5970 .

Daborn, C.J. \& Grange, J.M. (1993) HIV/AIDS and its implications for the control of animal tuberculosis. British Veterinary Journal 149, 405-417.

Dakkak, A. (2010) Echinococcosis/hydatidosis: a severe threat in Mediterranean countries. Veterinary Parasitology 174, 2-11. 
Eckert, J. \& Deplazes, P. (2004) Biological, epidemiological, and clinical aspects of echinococcosis, a zoonosis of increasing concern. Clinical Microbiology Reviews 17, 107-135.

Ernest, E., Nonga, H.E., Kynsieri, N. \& Cleaveland, S. (2009) A Retrospective Survey of Human Hydatidosis Based on Hospital Records During The Period 1990-2003 in Ngorongoro, Tanzania. Zoonoses and Public Health 57, e124-e129.

Etter, E., Donado, P., Jori, F., Caron, A., Goutard, F. \& Roger, F. (2006) Risk Analysis and Bovine Tuberculosis, a Re-emerging Zoonosis. Annals of the New York Academy of Sciences 1081, 61-73.

F“atkenheuer, G., Taelman, H., Lepage, P., Schwenk, A. \& Wenzel, R. (1999) The return of tuberculosis. Diagnostic Microbiology and Infectious Disease 34, 139-146.

Foster, E.N. \& Hertz, G. (2010) Echinococcus of the Liver Treated with Laparoscopic Hepatectomy. The Permanente Journal 14, 45-46

Geerts, S., Kumar, V. \& Abbeele O. van den (1980) Taenia saginata cysticercosis in slaughter cattle in Belgium. Vlaams Diergeneeskundig Tijdschrift 49, 365-374.

Gracey, J.F., Collins, D.S. \& Huey, R.J. (1999) Meat Hygiene, 10th ed. W.B. Saunders Company Ltd, pp. 261-287.

Hadorn, D.C. \& Stark, K.D.C. (2008) Evaluation and optimization of surveillance systems for rare and emerging infectious diseases. Veterinary Research 39, 57.

Hedberg, C.W., Levine, W.C., White, K.E., Carlson, R.H., Winsor, D.K., Cameron, D.N., MacDonald, K.L. \& Osterholm, M.T. (1992) An International foodborne Outbreak of Shigellosis Associated With a Commercial Airline. Journal of American Medical Association 268, 3208-3212.

Hyera, J.K.M. (1984) Prevalence, seasonal variation and economic significance of fasciolasis in cattle as observed in Iringa abattoir between 1976 and 1980. Bulletin of Animal Health and Production in Africa 32, 356- 359.

Jones, K.E., Patel, N.G., Levy, M.A., Storeygard, A., Balk D., Gittleman, J.L. \& Daszak, P. (2008) Global trends in emerging infectious diseases. Nature 451, 990-993.

Jongwutiwes, S., Putaporntip, C., Chantachum, N. \& Sampatanukul, P. (2004) Jejunal perforation caused by morphologically abnormal Taenia saginata infection. Journal of Infection 49, 324-328.

Joshi, D.D., Maharjan, M., Johansen, M.V., Willingham, A.L., \& Sharma, M. (2003) Improving meat inspection and control in resource-poor communities: the Nepal example. Acta Tropica 87, 119-127.

Kambarage, D.M., Kimera, S.I., Kazwala, R.R. \& Mafwere B.M. (1995) Disease conditions responsible for condemnation of carcasses and organs in short-horn Zebu cattle slaughtered in Tanzania. Preventive Veterinary Medicine 22, 249-255.

Karama, M., Johnson, R.P., Holtslander, R., McEwen, S.A. \& Gyles, C.L. (2008) Prevalence and characterization of verotoxin-producing Escherichia coli (VTEC) in cattle from an Ontario abattoir. Canadian Journal of Veterinary Research 72, 297-302.

Karanikas, I.D., Sakellaridis, T.E., Alexiou, C.P., Siaperas, P.A., Fotopoulos, A.C. \& Antsaklis, G.I. (2007) Taenia saginata: a rare cause of bowel obstruction. Transactions of the Royal Society of Tropical Medicine and Hygiene 101, 527-528.

Kebede, N., Mitiku, A. \& Tilahun, G. (2008) Hydatidosis of slaughtered animals in Bahir Dar Abattoir, Northwestern Ethiopia. Tropical Animal Health and Production 41, 43-50. 
Keyyu, J.D., Kassuku, A.A., Msalilwa, L.P., Monrad, J. \& Kyvsgaard, N.C. (2006) Crosssectional prevalence of helminth infection in cattle on traditional, small-scale and large-scale dairy farms in Iringa district, Tanzania. Veterinary Research Communications 30, 45-55.

Keyyu, J.D., Monrad, J., Kyvsgaard, N.C. \& Kassuku, A.A. (2005) Epidemiology of Fasciola gigantica and Amphistomes in cattle on traditional, small-scale dairy and large-scale dairy farms in the Southern Highlands of Tanzania. Tropical Animal Health and Production 37, 303-314.

Lahuerta, A., Westrell, T., Takkinen, J., Boelaert, F., Rizzi, V., Helwigh, B., Borck, B., Korsgaard, H., Ammon, A. \& Makela, P. (2011) Zoonoses in the European Union: Origin, distribution and dynamics - the EFSA-ECDC summary report 2009. EuroSurveillance $16 \quad$ (13): $\quad$ pII=19832. Available online: http://www.eurosurveillance.org/

Larson, H. (2000) The Economic Impacts of Tuberculosis, World Health Organization, Amsterdam, Holland.

Macpherson, C.N.L., Kachani, M., Lyagoubi, M., Berada, M., Bouslikhane, M., Shepherd, M., Fields, P.F. \& El Hasnaoui, E. (2004) Cystic echinococcosis in the Berber of the Mid Atlas Mountains, Morocco: new insights into the natural history of cystic hydatid disease in humans. Annals of Tropical Medicine and Parasitology 98, 481-490.

MAFS (2002) Basic Data-Agriculture Sector 1994/95-2000/2001. Statistics Unit, , Ministry of Agriculture Food Security, Dar es Salaam, Tanzania, August 2002, 72 pp.

Mas-Coma S., Bargues, M.D., Valero M.A. (2005) Fascioliasis and other plant borne zoonoses. International Journal of Parasitology 35, 1255-1278.

McLauchlan, I. (1981) Bovine cysticercosis survey. Veterinary Record 109 (13), 291.

Mellau, B.L., Nonga, H.E. \& Karimuribo, E.D. (2010) A slaughterhouse survey of liver lesions in slaughtered cattle, sheep and goats at Arusha, Tanzania. Research Journal of Veterinary Sciences 3, 179-188.

Mellau, B.L., Nonga, H.E. \& Karimuribo, E.D. (2011) Slaughter stock abattoir survey of carcasses and organ/offal condemnations in Arusha Region, northern Tanzania. Tropical Animal Health and Production 43, 857-864.

Morris, R.S., Pfeiffer, D.U. \& Jackson, R. (1994) The epidemiology of Mycobacterium bovis infections. Veterinary Microbiology, 40(1-2) 153-177.

Mwabonimana, M-F. Kassuku, A.A. Ngowi, H.A. Mellau, L.S.B. Nonga H.E. \& Karimuribo E.D. (2009) Prevalence and economic significance of bovine fasciolosis in slaughtered cattle at Arusha abattoir, Tanzania. Tanzania Veterinary Journal 26, 68-74.

Nonga, H.E. \& Karimuribo, E.D. (2009) A retrospective survey of hydatidosis in livestock in Arusha, Tanzania, based on abattoir data during 2005-2007. Tropical Animal Health and Production 41, 1253-1257.

Nonga, H.E., Mwabonimana M.F., Ngowi H.A., Mellau L.S.B. \& Karimuribo, E.D. (2009) A retrospective survey of liver fasciolosis and stilesiosis in livestock based on abattoir data in Arusha, Tanzania. Tropical Animal Health and Production 41, 1377-1380.

O'Reilly L. M. \& Daborn, C. J. (1995) The epidemiology of Mycobacterium bovis infections in animals and man: a review. Tubercle and Lung Disease 76, 1-46.

Ogunremi, O., MacDonald, G., Geerts, S. \& Brandt, J. (2004) Diagnosis of Taenia Saginata Cysticercosis by Immunohistochemical test on formalin-fixed and paraffinembedded bovine lesions. Journal of Veterinary Diagnostic Investigation 16, 438. 
Pawlowski, Z.S. \& Murrell, K.D. (2001) Taeniasis and cysticercosis. In: Hui, Y.H., Sattar, S.A., Murrell, K.D., Nip, W.K. \& Stanfield, P.S. (Editors), Foodborne Disease Handbook: Viruses, Parasites, Pathogens and HACCP. Vol 2. Marcel Dekker, New York, pp 217-27.

Silverman, P.H. \& Hulland, T.J. (1961) Histological observation on bovine cysticercosis. Research in Veterinary Science 2, 248-252.

Sotiraki, S. \& Chaligiannis, I. (2010) Cystic echinococcosis in Greece. Past and present. Parasite 17, 205-210.

Swai, E.S., Mtui, P.F., Mbise, A.N., Kaaya, E., Sanka, P. \& Loomu P.M. (2006) Prevalence of gastro intestinal parasite infections in Maasai cattle in Ngorongoro District, Tanzania. Livestock Research for Rural Development 18, 107.

Tassew, H., Abdissa, A., Beyene, G., \& Gebre-selassie, S. (2010) Microbial flora and food borne pathogens on minced meat and their susceptibility to antimicrobial agents. Ethiopian Journal of Health Sciences 20, 137-143.

Thoen, C., LoBue, P. \& de Kantor, I. (2006a) The importance of Mycobacterium bovis as a zoonosis. Veterinary Microbiology 112, 339-345.

Thoen, C.O. \& Ebel, E.D. (2006b) Diagnostic tests for bovine tuberculosis, In: Thoen, C.O., Steele, J.H. \& Gilsdorf, M.J. (Eds), Mycobacterium Bovis Infection in Animals and Humans. $2^{\text {nd }}$ edition. pp. 49-53, Blackwell Publishing, Des Moines, Iowa, USA,

Thoen, C.O., LoBue, P., Enarson, D.A., Kaneene, J.B. \& de Kantor, I.N. (2009) Tuberculosis: a re-emerging disease of animals and humans. Veterinaria Italiana 45, 135-181.

Torgerson, P.R. (2003) Economic effects of echinococcosis. Acta Tropica 85, 113-118.

United Republic of Tanzania (2002) Population and housing census [http://www.tanzania.go.tz/census/districts/morogorourban.htm].

Van Metre, D.C., Barkey, D.Q., Salman, M.D. \& Morley, P.S. (2009) Development of a syndromic surveillance system for detection of disease among livestock entering an auction market. Journal of the American Veterinary Medical Association 234, 658-664.

Vilas, V.J.D.R., Bohning, D. \& Kuhnert, R. (2008) A comparison of the active surveillance of scrapie in the European Union. Veterinary Research 39, 37-52.

Vourc'h, G., Bridges, V.E., Gibbens, J., De Groot, B.D., McIntyre, L., Poland, R. \& Barnouin, J. (2006) Detecting emerging diseases in farm animals through clinical observations. Emerging Infectious Diseases 12, 204-210.

WHO (2009) Global Tuberculosis Control: Epidemiology, Strategy, Financing, World Health Organization, Geneva, Switzerland, WHO report 2009.

WHO (2010) WHO - Zoonoses. Geneva: World Health Organization. World Health Organization website (accessed 2011) http://www. who.int/topics/zoonoses/en/.

Woolhouse, M. \& Gaunt, E. (2007) Ecological origins of novel human pathogens. Critical Reviews in Microbiology 33, 231-242. 